\title{
Comparisons between small intestinal and gastric feeding in severe traumatic brain injury: a systematic review and meta-analysis of randomized controlled trials
}

\author{
Dong Wang, MD, ${ }^{1,2}$ Shao-Qin Zheng, MD, ${ }^{1}$ Xian-Cai Chen, MD, ${ }^{2}$ Shi-Wen Jiang, MD, ${ }^{3}$ and \\ Hai-Bin Chen, MD, PhD',2
}

\begin{abstract}
'Department of Neurosurgery, The First Affiliated Hospital of Shantou University Medical College; ${ }^{2}$ Department of Histology and Embryology, Shantou University Medical College, Shantou, Guangdong, China; and '3Department of Biomedical Science, Mercer University School of Medicine, Savannah, Georgia
\end{abstract}

\begin{abstract}
OBJECT Nutritional support is highly recommended for reducing the risk of nosocomial infections, such as pneumonitis, in patients with severe traumatic brain injury (TBI). Currently, there is no consensus for the preferred route of feeding. The authors compared the risks of pneumonitis and other important outcomes associated with small intestinal and gastric feeding in patients with severe TBI.
\end{abstract}

METHODS This systematic review and meta-analysis was conducted according to the Preferred Reporting Items for Systematic Reviews and Meta-Analyses (PRISMA) guidelines. Relevant randomized controlled trials (up to December 16,2013 ) that compared small bowel to gastric feeding in patients with severe TBI were identified from searches in the PubMed and Embase databases. The primary outcome was risk of pneumonia. Secondary outcomes included ventilatorassociated pneumonia, mortality, length of intensive care unit stay, length of hospital stay, duration of mechanical ventilation, total number of complications, aspiration, diarrhea, distention, Glasgow Coma Scale score, Injury Severity Score, and Acute Physiology and Chronic Health Evaluation II score.

RESULTS Five randomized controlled trials with 325 participants in total were included in the meta-analysis. Compared with gastric feeding, small bowel feeding was associated with a significant reduction in the incidence of pneumonitis (risk ratio $[R R] 0.67 ; 95 \% \mathrm{Cl} 0.52-0.87 ; p=0.002 ;\left.\right|^{2}=0.0 \%$ ) and ventilator-associated pneumonia $(\mathrm{RR} 0.52 ; 95 \% \mathrm{Cl}$ $\left.0.34-0.81 ; p=0.003 ; I^{2}=0.0 \%\right)$. Small intestinal feeding was also associated with a decrease in the total number of complications (RR $0.43 ; 95 \% \mathrm{Cl} 0.20-0.93 ; p=0.03 ; 1^{2}=68 \%$ ). However, small intestinal feeding did not seem to significantly convert any of the other end points in the meta-analysis.

CONCLUSIONS The limited evidence suggests that small bowel feeding in patients with severe TBI is associated with a risk of pneumonia that is lower than that with gastric feeding. From this result, the authors recommend the use of small intestinal feeding to reduce the incidence of pneumonitis in patients with severe TBI.

http://thejns.org/doi/abs/10.3171/2014.11.JNS141109

KEY WORDS enteral nutrition; traumatic brain injury; small bowel feeding; gastric feeding; meta-analysis

$\mathrm{S}$ EVERE traumatic brain injury (TBI) is a catastrophic event that often has destructive familial, economic, and societal consequences. It contributes to many deaths and cases of permanent disability, especially among patients $15-30$ years old. ${ }^{8,10}$ The average mortality rate for patients with severe TBI is $39 \%$, and $60 \%$ of these patients have an unfavorable outcome on the Glasgow Outcome
Scale. ${ }^{24,26}$ Furthermore, those who survive tend to have significant disabilities, which also can cause a major socioeconomic burden.

Patients with severe TBI have reduced immune function and higher risks of nosocomial infections as a result of decreased energy and increased protein catabolism.,7 By providing additional daily calories, nutrition support

ABBREVIATIONS APACHE II = Acute Physiology and Chronic Health Evaluation II; GCS = Glasgow Coma Scale; ICU = intensive care unit; ISS = Injury Severity Score; $\mathrm{MV}=$ mechanical ventilation; $\mathrm{RCT}$ = randomized controlled trial; $\mathrm{RR}=$ risk ratio; $\mathrm{TBI}$ = traumatic brain injury; $\mathrm{VAP}$ = ventilator-associated pneumonia; $\mathrm{WMD}=$ weighted mean difference.

SUBMITTED May 20, 2014. ACCEPTED November 12, 2014.

INCLUDE WHEN CITING Published online May 29, 2015; DOI: 10.3171/2014.11.JNS141109.

DISCLOSURE The authors report no conflict of interest concerning the materials or methods used in this study or the findings specified in this paper. 
therapy has been shown to improve the treatment for this metabolic disorder in patients with severe TBI. ${ }^{28}$ Because of its secretagogue and immunological effects on intestinal function, the enteral route is preferred for providing nutrition support therapy. This route is also associated with a lower rate of nosocomial infections, particularly for episodes of pneumonia, ${ }^{1}$ and the frequency of its incorporation into the management of critically ill patients has been increasing. ${ }^{14}$ However, the enteral route is often underestimated and neglected for patients with severe TBI.

Although the recommendation by the Brain Trauma Foundation is to achieve full caloric replacement within 7 days after severe TBI, ${ }^{6}$ there is still no consensus regarding the optimal route of feeding (i.e., via small intestinal or gastric feeding). Patients with severe TBI have an increased incidence of gastrointestinal complications, particularly gastric residuals; not only is the brain trauma itself associated with this increase, but the therapeutics used to control intracranial hypertension and other measures of patient support may also contribute to this effect. One advantage of small intestinal feeding over gastric feeding may be a reduced risk of gastroesophageal reflux and subsequent aspiration pneumonia. ${ }^{1}$

The ideal route for enteral feeding remains to be established. Adequately powered data derived from randomized controlled trials (RCTs) in which small intestinal feeding and gastric feeding in patients with severe TBI were compared are scarce. Therefore, we performed this meta-analysis and systematic review to compare small intestinal and gastric feeding in patients with severe TBI in regard to the risks of pneumonitis and other important outcomes.

\section{Methods}

\section{Literature Search and Inclusion Criteria}

This systematic review and meta-analysis was conducted according to Preferred Reporting Items for Systematic Reviews and Meta-Analyses (PRISMA) guidelines.

Relevant articles, published up to December 16, 2013, were identified by 2 of the authors (D.W. and S.Q.Z.) through searches of the PubMed and Embase databases. Limiting the search to RCTs in which human subjects were used, the search strategy was (gastric OR nasogastric) AND (small bowel OR small intestinal OR duodeno OR jejuno OR nasojejunal OR nasoduodenal OR postpyloric OR transpyloric) AND (feeding OR enteral nutrition) AND (trauma OR burn). Only articles written in the English language were included. In addition, manual checks of the reference lists of identified studies were performed to include other potentially eligible trials. This entire process was repeated until we could not identify any additional articles. We used only the studies that included patients with severe TBI who required mechanical ventilation (MV), compared small intestinal and gastric feeding, and had data available on the incidence of pneumonitis. Disease severity was determined from the Glasgow Coma Scale (GCS) scores, ${ }^{27}$ Injury Severity Scores (ISSs), ${ }^{5}$ and Acute Physiology and Chronic Health Evaluation II (APACHE II) scores. ${ }^{15}$

\section{Data Extraction and Outcome Measures}

Two authors (D.W. and S.Q.Z.) independently extracted the following data from each report: first author name, year of publication, country, number of patients, participant characteristics, severity of illness, tube type and placement technique for patients in the small intestinal feeding group and those in the gastric feeding group, and the study's definition of pneumonitis. Two additional authors (S.W.J. and H.B.C.) checked the data after they were entered into a standardized Excel (Microsoft Corp.) file. After discussion, any disagreements were resolved and a consensus was formed. The incidence of pneumonitis was the primary outcome of the study. However, the definitions of pneumonitis varied among the studies. The secondary outcomes included ventilator-associated pneumonia (VAP), mortality, length of intensive care unit (ICU) stay, length of hospital stay, duration of MV, total number of complications, aspiration, diarrhea, distention, GCS score, ISS, and APACHE II score.

\section{Quality Assessment}

The Cochrane risk-of-bias tool was used to evaluate the methodologic quality of each trial. In each included trial, the risk of bias for each outcome was reported as low, unclear, or high in the following domains: random sequence generation, allocation concealment, blinding of participants and personnel, blinding of outcome assessment, incomplete outcome data, selective reporting, and other biases. ${ }^{3,12}$ We used a funnel plot to uncover potential publication bias.

\section{Statistical Analysis}

Differences are expressed as risk ratios (RRs) with $95 \%$ CIs for dichotomous outcomes and weighted mean differences (WMDs) with $95 \%$ CIs for continuous outcomes. Heterogeneity across the studies was tested using the $\mathrm{I}^{2}$ statistic, which is a quantitative measure of inconsistency across studies. Studies with low heterogeneity have an $\mathrm{I}^{2}$ value of $25 \%-50 \%$, those with moderate heterogeneity have an $\mathrm{I}^{2}$ value of $50 \%-75 \%$, and those with high heterogeneity have an $\mathrm{I}^{2}$ value of $>75 \% .{ }^{13} \mathrm{~A}$ random-effects model was used regardless of heterogeneity.

Additional sensitivity analyses were conducted to explore possible explanations for heterogeneity in the patient characteristics, definitions of pneumonitis, and other confounding factors among the studies. The influence of various exclusion criteria on the overall pooled estimate was also examined by using these analyses. Furthermore, the influence of a single study on the overall pooled estimate was also investigated by omitting 1 study in each turn. However, these analyses were performed for pneumonitis only, because only a small number of studies examined other outcomes.

The Begg funnel plots (log odds ratios vs standard errors) were visually inspected to assess potential publication bias. The presence of publication bias was also evaluated by using the Begg and Egger tests. A p value of $<0.05$ was judged to be statistically significant, except where otherwise specified. All statistical analyses were performed by using Review Manager (RevMan) version 


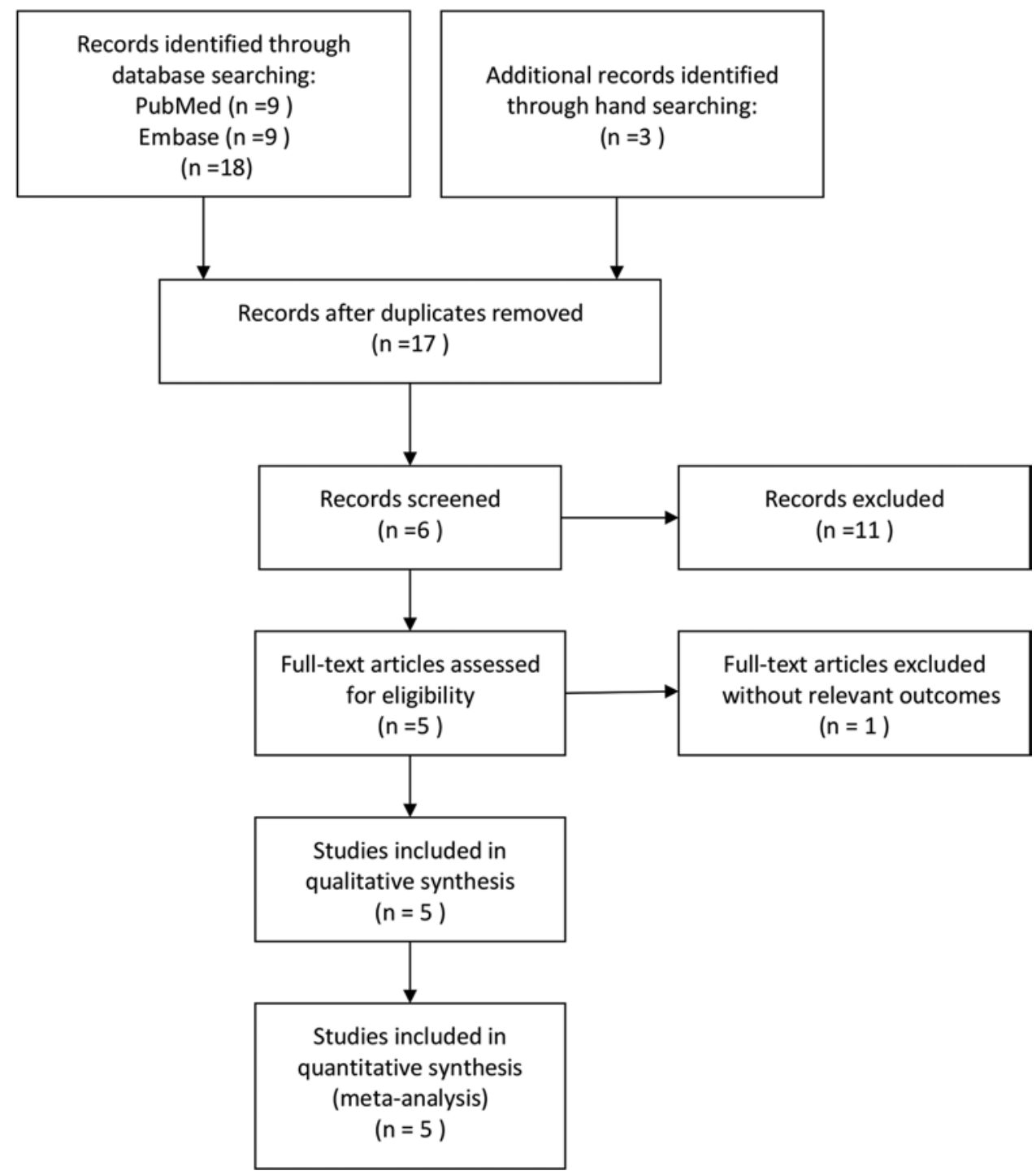

FIG. 1. Flow diagram showing selection of the studies for this meta-analysis.

5.2.6 (Nordic Cochrane Centre) and Stata version 12.0 (Stata Corp).

\section{Results}

\section{Identification and Selection of Studies}

In the initial database search, we identified 18 RCTs. Four RCTs were excluded because of duplicate studies, and 11 RCTs were excluded based on the titles and abstracts. The remaining 3 full-text articles ${ }^{1,16,20}$ were reviewed for more detailed evaluation, and one ${ }^{20}$ of them was excluded because pneumonia was not an outcome. Three additional RCTs were identified through manual searching. Finally, 5 RCTs that met our inclusion criteria were included in the meta-analysis. ${ }^{1,11,16,21,25}$ The search flow diagram is shown in Fig. 1.

\section{Study Characteristics}

The main characteristics of the patients and related def- initions of pneumonia in the 5 included RCTs, which were published between 1989 and 2010, are presented in Tables 1 and 2. The sample sizes of these RCTs ranged from 27 to 104 (total sample size 325).

All 5 studies included here reported pneumonitis events and GCS scores; ${ }^{1,11,16,21,25} 4$ reported mortality ${ }^{1,16,21,25}$ and lengths of ICU stay; ${ }^{1,11,16,21} 3$ reported lengths of hospital stay, ${ }^{1,16,21}$ duration of MV, ${ }^{1,16,21}$ ISSs, ${ }^{16,21,25}$ and APACHE II scores; ${ }^{1,16,25}$ and 2 reported VAP events, ${ }^{1,16}$ total number of complications, ${ }^{1,25}$ aspiration, ${ }^{1,21}$ diarrhea, ${ }^{1,21}$ and distention. ${ }^{1,21}$ The quality of the included studies was assessed by the Cochrane risk-of-bias tool.

\section{Risk of Bias}

A funnel plot (Fig. 2) of the included studies did not suggest the presence of publication bias. This result was confirmed statistically by using the Egger test (bias 0.05; $95 \% \mathrm{CI}-1.29$ to $1.33 ; \mathrm{p}=0.965$ ). 
TABLE 1. Main characteristics of included RCTs

\begin{tabular}{|c|c|c|c|c|}
\hline Authors \& Year & Country & $\begin{array}{l}\text { No. of Patients } \\
\text { (small intestinal vs } \\
\text { gastric group) }\end{array}$ & Patient Population Details & Severity of IIIness (small intestinal vs gastric group) \\
\hline Grahm et al., 1989 & USA & 32 (17 vs 15) & Severe TBI, GCS score $<10$ & Mean GCS score: 5.1 vs 7.1 \\
\hline Taylor et al., 1999 & UK & 82 (41 vs 41) & $\begin{array}{l}\text { Severe TBI, required MV, } \\
\text { GCS score }>3\end{array}$ & $\begin{array}{l}\text { Median GCS score: } 9 \text { (range } 7-10 \text { ) vs } 8 \text { (range } 7-9 \text { ) } \\
\text { Median APACHE II score: } 14 \text { (range } 12-17 \text { ) vs } 14 \text { (range 13-18) } \\
\text { Median ISS: } 26 \text { (range } 25-29 \text { ) vs } 25 \text { (range } 25-26 \text { ) }\end{array}$ \\
\hline Kortbeek et al., 1999 & Canada & $\begin{array}{l}80 \text { (37 vs 43) (TBI: } \\
62 / 80[28 / 37 \text { vs } \\
34 / 43])\end{array}$ & $\begin{array}{l}\text { Severe trauma (main TBI: } \\
62 / 80 \text { ), required MV for } \\
\geq 48 \mathrm{hrs}, \text { ISS } \geq 16\end{array}$ & $\begin{array}{l}\text { Median GCS score: } 5 \text { (range } 3-15) \text { vs } 6 \text { (range } 3-15) \\
\text { Mean }( \pm S D) \text { APACHE II score: } 18.0 \pm 7.4 \text { vs } 18.0 \pm 6.0 \\
\text { Mean }( \pm S D) \text { ISS: } 33 \pm 9.7 \text { vs } 30.0 \pm 11\end{array}$ \\
\hline Minard et al., 2000 & USA & 27 (12 vs 15) & $\begin{array}{l}\text { Severe TBI, required MV, } \\
\text { GCS score of }>3 \text { and }<11\end{array}$ & $\begin{array}{l}\text { Mean }( \pm S D) \text { GCS score: } 7 \pm 1 \text { vs } 7 \pm 2 \\
\text { Mean }( \pm S D) \text { ISS: } 31 \pm 13 \text { vs } 30 \pm 11\end{array}$ \\
\hline $\begin{array}{l}\text { Acosta-Escribano et } \\
\text { al., } 2010\end{array}$ & Spain & 104 (50 vs 54$)$ & $\begin{array}{l}\text { Severe TBI, required MV, } \\
\text { GCS score }<9\end{array}$ & $\begin{array}{l}\text { Mean }( \pm S D) \text { GCS score: } 6 \pm 3 \text { vs } 6 \pm 3 \\
\text { Mean }( \pm S D) \text { APACHE II score: } 16 \pm 4 \text { vs } 18 \pm 5 \\
\text { Mean }( \pm S D) \text { SOFA score: } 5 \pm 2 \text { vs } 5 \pm 2\end{array}$ \\
\hline
\end{tabular}

SOFA = Sequential Organ Failure Assessment.

In Figs. 3 and 4, we report the methodologic quality assessment, for which the Cochrane risk-of-bias tool was used for each trial. Overall, 1 study was judged to be at low risk of bias and 4 at high risk of bias, and 2 had an unclear risk of bias. A lack of blinding was considered to have a low effect on mortality outcome; therefore, this outcome was to have a low risk of bias. However, when assessing other less objective outcomes (e.g., pneumonia), a lack of blinding can introduce performance or ascertain- ment bias; therefore, these outcomes were considered to have a high risk of bias in this setting. ${ }^{3}$

\section{Primary Outcome}

A total of 325 patients -157 in the small intestinal feeding group and 168 in the gastric feeding group-were included in this analysis. Figure 5 shows the pooled results from the random-effects model combining the RRs for overall pneumonitis. Compared with gastric feeding,

TABLE 2. Key definitions and criteria in the study designs of the included RCTs

\begin{tabular}{|c|c|c|c|}
\hline Study & Small Intestinal Group & Gastric Group & Pneumonia \\
\hline Grahm et al., 1989 & $\begin{array}{l}\text { Fed w/in } 36 \text { hrs of admission by a sepa- } \\
\text { rate nasojejunal feeding tube placed } \\
\text { fluoroscopically }\end{array}$ & $\begin{array}{l}\text { Fed gastrically after Day } 3 \\
\text { or when gastric function } \\
\text { returned }\end{array}$ & $\begin{array}{l}\text { Culture-positive bronchitis w/ signs of infiltrate on } \\
\text { chest radiograph }\end{array}$ \\
\hline Taylor et al., 1999 & $\begin{array}{l}\text { An Accusite pH sensor tube placed by } \\
\text { the "blind" technique into the intestine; } \\
\text { tube position confirmed by abdomi- } \\
\text { nal radiography; intestinal feeding } \\
\text { maintained at full rate regardless of } \\
\text { gastric residual }\end{array}$ & $\begin{array}{l}\text { A gastric residual of } \leq 200 \mathrm{ml} \\
\text { was the threshold of toler- } \\
\text { ance for gastric feeding }\end{array}$ & Not described \\
\hline Kortbeek et al., 1999 & $\begin{array}{l}\text { Nasal or oral transpyloric feeding tubes; } \\
\text { placed in the radiology department } \\
\text { using fluoroscopy for guidance \& } \\
\text { confirmation }\end{array}$ & Not described & $\begin{array}{l}\text { VAP defined as new infiltrate on radiograph of }>48 \\
\text { hrs duration \& at least } 2 \text { of the following: temp } \\
>38.5^{\circ} \mathrm{C} \text { or }<35^{\circ} \mathrm{C}, \text { WBC count of }>10,000 / \mathrm{mm}^{3} \\
\text { or }<3000 / \mathrm{mm}^{3} \text {, purulent sputum, or isolation of } \\
\text { pathogenic bacteria from an endotracheal aspi- } \\
\text { rate; radiographic infiltrate \& positive quantita- } \\
\text { tive culture from BAL fluid was also considered } \\
\text { diagnostic for pneumonia }\end{array}$ \\
\hline Minard et al., 2000 & $\begin{array}{l}\text { Nasoenteric tube, placed endoscopi- } \\
\text { cally; feeding began within } 60 \mathrm{hrs} \text { of } \\
\text { injury }\end{array}$ & Small-bore nasogastric tube & $\begin{array}{l}\text { New or changing infiltrate on chest radiograph, } \\
\text { purulent sputum, temp of }>38.3^{\circ} \mathrm{C}, \& \text { elevated } \\
\text { WBC count of }>12,000 / \mathrm{mm}^{3} \text { or BAL fluid with } \\
>100,000 \text { CFU }\end{array}$ \\
\hline $\begin{array}{l}\text { Acosta-Escribano et } \\
\text { al., } 2010\end{array}$ & $\begin{array}{l}\text { Double-lumen tube (Compat Stay-Put } \\
\text { 9/18) }\end{array}$ & 12-Fr tube & $\begin{array}{l}\text { Pneumonia assessed with CPIS of }>6 \text {; VAP } \\
\text { defined at } 48 \text { hrs after admission }\end{array}$ \\
\hline
\end{tabular}

$\mathrm{BAL}=$ bronchoalveolar lavage; $\mathrm{CFU}=$ colony-forming unit; $\mathrm{CPIS}=$ clinical pulmonary infection score; temp = temperature; WBC = white blood cell. 


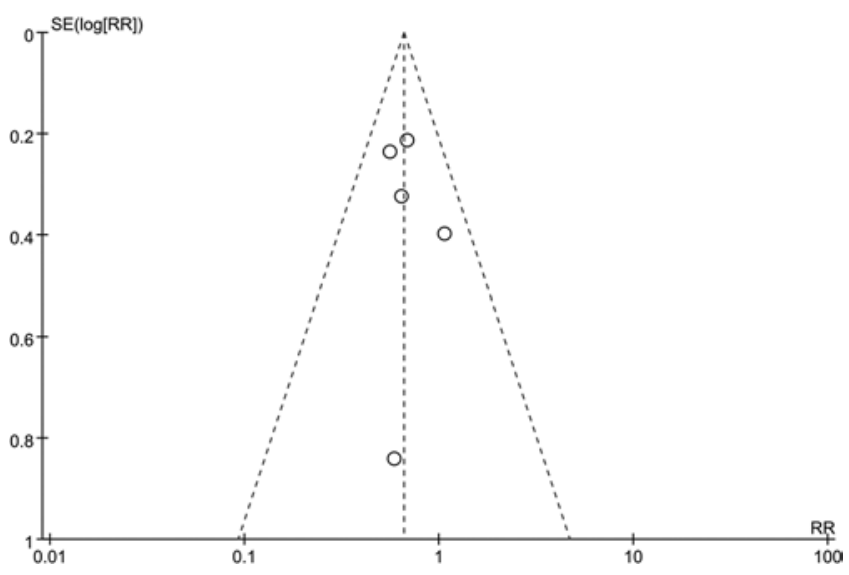

FIG. 2. Funnel plot for the detection of publication bias. The figure was created for visual testing of publication bias by plotting the standard error (SE)( $\log [R R])$ against RR and then examining the figure for symmetry. The funnel plot of the studies that evaluated the effects of feeding routes on overall pneumonitis seems to be symmetrical.

small intestinal feeding was associated with a significant reduction in the overall incidence of pneumonitis (risk ratio $[R R] 0.67 ; 95 \% \mathrm{CI} 0.52-0.87 ; \mathrm{p}=0.002)$, with low heterogeneity among the studies $\left(\mathrm{I}^{2}=0.0 \% ; \mathrm{p}=0.73\right)$. Further exclusion of any single study did not materially alter the overall combined RR for pneumonitis, which ranged from 0.63 (95\% CI 0.48-0.83; p = 0.0001) to 0.73 (95\% CI $0.53-0.99 ; \mathrm{p}=0.04)$.

\section{Secondary Outcomes}

Tables 3 and 4 outline the secondary outcomes. Compared with gastric feeding, small intestinal feeding was associated with a significant reduction in VAP (RR 0.52; 95\% CI $0.34-0.81 ; \mathrm{p}=0.003)$, with low heterogeneity among the studies $\left(\mathrm{I}^{2}=0.0 \% ; \mathrm{p}=0.38\right)$, and was associated with a decrease in the total number of complications (RR 0.43; 95\% CI 0.20-0.93; $\mathrm{p}=0.03$ ). However, small intestinal feeding was not associated with decreases in mortality (RR 0.81 ; 95\% CI $0.44-1.47 ; \mathrm{p}=0.49$ ), aspiration (RR 0.23; 95\% CI 0.03-1.90; $\mathrm{p}=0.17$ ), diarrhea (RR $1.05 ; 95 \%$ CI 0.29-3.86; $\mathrm{p}=0.94$ ), or distention (RR 0.71; $95 \%$ CI $0.32-1.58 ; \mathrm{p}=0.41)$ in comparison with gastric feeding.

Small intestinal feeding also had no impact on length of ICU stay (WMD 2.25 days; 95\% CI -6.74 to 11.24 days; $\mathrm{p}=0.62$ ), length of hospital stay (WMD 2.66 days; 95\% CI -8.80 to 14.12 days; $\mathrm{p}=0.65$ ), or duration of MV (WMD 1.03 days; $95 \%$ CI -5.06 to 7.12 days; $p=0.74$ ). Furthermore, the patients who received small intestinal feeding did not significantly differ from those who received gastric feeding in GCS score (WMD 0.00; $95 \%$ CI -0.82 to $0.82 ; \mathrm{p}=1.00$ ), ISS (WMD 2.61; 95\% CI -1.46 to $6.68 ; \mathrm{p}$ $=0.21$ ), or APACHE II score (WMD $-1.38 ; 95 \%$ CI -3.19 to $0.43 ; \mathrm{p}=0.13$ ).

\section{Publication Bias}

Visual inspection of the funnel plot (Fig. 2) did not indicate a publication bias. However, the low power of this

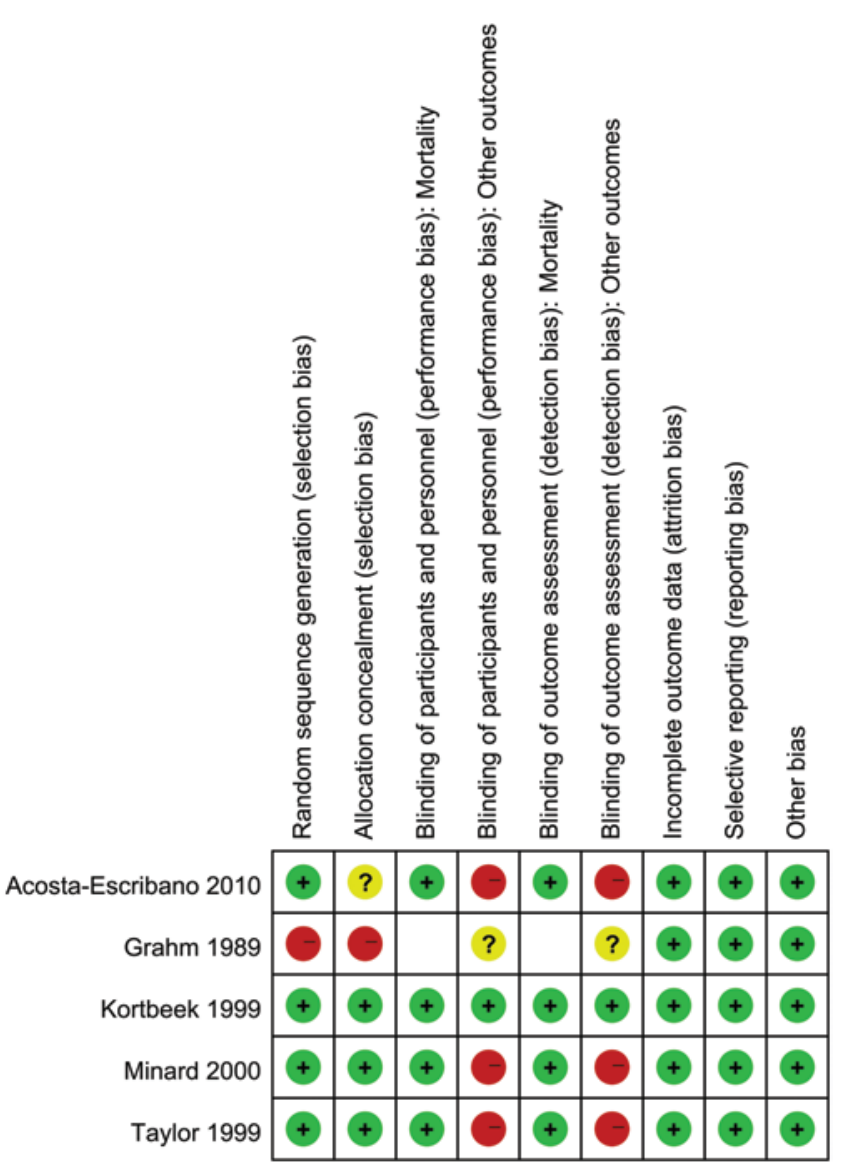

FIG. 3. Risk-of-bias summary. Shown is the assessment of risk of bias for each trial in our meta-analysis using the Cochrane risk-of-bias tool. Green symbols correspond to low risk of bias, yellow to unclear risk of bias, and red to high risk of bias. Figure is available in color online only.

analysis, resulting from the inclusion of only 5 studies, limited the interpretability of this finding.

\section{Discussion}

This systematic review and meta-analysis of RCTs comparing the route of feeding in patients with severe TBI demonstrates that delivery of nutrients directly into the small intestine may be associated with a reduction in the incidence of pneumonia (including VAP) and total complications when compared with gastric delivery. However, the route of feeding did not affect mortality, length of ICU stay, length of hospital stay, duration of MV, aspiration, diarrhea, or distention. Also, there was an indication that feeding into the small intestine increased nutrient intake, but a meta-analysis was not conducted because of the marked variation in the reporting of nutritional outcomes. ${ }^{1,11,16,25}$

The mechanism by which small intestinal feeding may reduce pneumonia rates remains unclear. One hypothesis, which explains the unfavorable outcome of gastric feeding, is that the increased gastric residual volume leads to regurgitation and aspiration, which leads to a higher incidence of nosocomial pneumonia. ${ }^{28}$ However, the results of 
Random sequence generation (selection bias)

Allocation concealment (selection bias)

Blinding of participants and personnel (performance bias): Mortality Blinding of participants and personnel (performance bias): Other outcomes

Blinding of outcome assessment (detection bias): Mortality Blinding of outcome assessment (detection bias): Other outcomes Incomplete outcome data (attrition bias)

Selective reporting (reporting bias)

Low risk of bias Unclear risk of bias High risk of bias

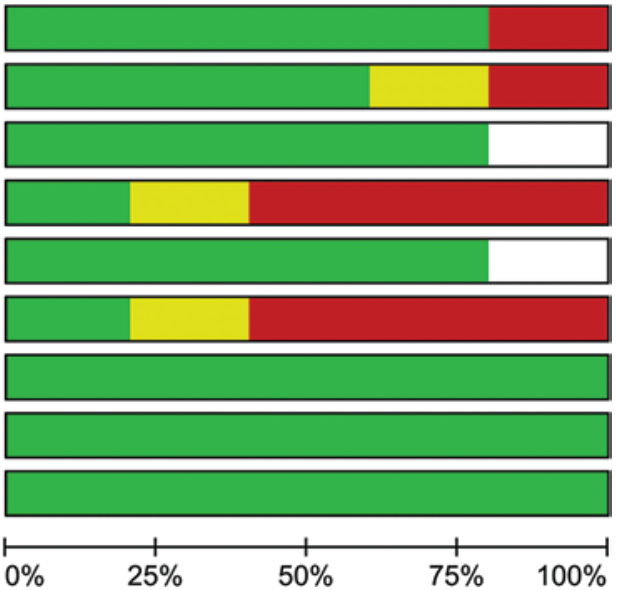

FIG. 4. Risk-of-bias graph. Using the Cochrane risk-of-bias tool, each risk-of-bias item is presented as a percentage across all included studies in this meta-analysis. Figure is available in color online only.

\begin{tabular}{|c|c|c|c|c|c|c|c|c|c|c|}
\hline Study or Subgroup & \multicolumn{2}{|c|}{ Small Intestinal } & \multicolumn{2}{|c|}{ Gastric } & \multicolumn{3}{|c|}{ Risk Ratio } & \multicolumn{3}{|c|}{ Risk Ratio } \\
\hline Grahm 1989 & 2 & 17 & 3 & 15 & $2.5 \%$ & $0.59[0.11,3.06]$ & 1989 & & & \\
\hline Kortbeek 1999 & 10 & 37 & 18 & 43 & $16.6 \%$ & $0.65[0.34,1.22]$ & 1999 & & & \\
\hline Taylor 1999 & 18 & 41 & 26 & 41 & $38.7 \%$ & $0.69[0.46,1.05]$ & 1999 & & & \\
\hline Minard 2000 & 6 & 12 & 7 & 15 & $11.0 \%$ & $1.07[0.49,2.34]$ & 2000 & & & \\
\hline Acosta-Escribano 2010 & 16 & 50 & 31 & 54 & $31.2 \%$ & $0.56[0.35,0.89]$ & 2010 & & & \\
\hline Total $(95 \% \mathrm{Cl})$ & & 157 & & 168 & $100.0 \%$ & $0.67[0.52,0.87]$ & & & & \\
\hline Total events & 52 & & 85 & & & & & & & \\
\hline $\begin{array}{l}\text { Heterogeneity: } \operatorname{Tau}^{2}=0 \\
\text { Test for overall effect: } Z\end{array}$ & $\begin{array}{l}\mathrm{Chi}^{2}=2 \\
3.04(\mathrm{P}=\end{array}$ & $\begin{array}{l}\mathrm{df}=4 \\
02)\end{array}$ & $(P=0.73$ & $; 1^{2}=$ & & & & $\begin{array}{cc}0.5 & 0.7 \\
\text { Small Intestinal }\end{array}$ & $\begin{array}{lr}1 & 1.5 \\
\text { Gastric }\end{array}$ & 2 \\
\hline
\end{tabular}

FIG. 5. Pneumonia. Five studies reported the incidence of overall pneumonia. Shown is a forest plot comparing small bowel feeding and gastric feeding with respect to pneumonia outcome. Results are shown by using a random-effects model with RR and $95 \%$ Cls. $\mathrm{M}-\mathrm{H}=$ Mantel-Haenszel (method). Figure is available in color online only.

multiple studies have indicated that there is no relationship between residual gastric volume and the risk of aspiration and that the absence of gastric-volume monitoring is not inferior to routine residual gastric-volume monitoring in the development of VAP. ${ }^{22,23}$ Our meta-analysis also did not find a significant difference in the risk of clinically detected aspiration of feeding.

Because of their intense catabolism and prolonged fasting, patients with TBI require specialized nutritional support. The gastrointestinal route is optimal for nutrient administration. ${ }^{2}$ Although the data on feeding complications are scarce, we are inclined to agree with Spanish Society of Intensive Care Medicine and Coronary Units-Spanish Society of Parenteral and Enteral Nutrition (SEMICYUCSENPE) and European Society for Clinical Nutrition and Metabolism (ESPEN) guidelines, which recommend enteral nutrition by the transpyloric route for patients with brain injury. In comparison with the gastric route, the transpyloric route is well tolerated, improves the efficacy in enteral supply, and reduces the incidence of late pneumonia. ${ }^{2,11,17}$

Using the Cochrane risk-of-bias tool, we evaluated the methodologic quality of each trial included in this study.

TABLE 3. Clinical outcomes: dichotomous data

\begin{tabular}{lcccccccc}
\hline \multicolumn{1}{c}{ Outcome } & $\begin{array}{c}\text { No. of } \\
\text { Patients }\end{array}$ & $\begin{array}{c}\text { No. of } \\
\text { Trials }\end{array}$ & $\begin{array}{c}\text { Small Bowel } \\
\text { Group }(\mathrm{n} / \mathrm{N})\end{array}$ & $\begin{array}{c}\text { Gastric } \\
\text { Group }(\mathrm{n} / \mathrm{N})\end{array}$ & RR $(95 \% \mathrm{Cl})$ & $\mathrm{p} \mathrm{Value}$ & $\mathrm{I}^{2}(\%)$ & $\begin{array}{c}\mathrm{p} \text { Value for } \\
\text { Heterogeneity }\end{array}$ \\
\hline VAP & 189 & 2 & 21 of 87 & 45 of 97 & $0.52(0.34-0.81)$ & 0.0003 & 0 & 0.38 \\
\hline Mortality & 293 & 4 & 13 of 140 & 22 of 153 & $0.81(0.44-1.49)$ & 0.49 & 0 & 0.64 \\
\hline Total complications & 186 & 2 & 22 of 91 & 52 of 95 & $0.43(0.20-0.93)$ & 0.03 & 68 & 0.08 \\
\hline Aspiration & 131 & 2 & 0 of 62 & 4 of 69 & $0.23(0.03-1.90)$ & 0.17 & 0 & 0.95 \\
\hline Diarrhea & 131 & 2 & 15 of 62 & 16 of 69 & $1.05(0.29-3.86)$ & 0.94 & 78 & 0.03 \\
\hline Distention & 131 & 2 & 5 of 62 & 10 of 69 & $0.71(0.32-1.58)$ & 0.41 & 0 & 0.39 \\
\hline
\end{tabular}


TABLE 4. Clinical outcomes: continuous data

\begin{tabular}{lcccccc}
\hline \multicolumn{1}{c}{ Outcome } & $\begin{array}{c}\text { No. of } \\
\text { Patients }\end{array}$ & $\begin{array}{c}\text { No. of } \\
\text { Trials }\end{array}$ & WMD $(95 \%$ CI) & p Value & I $(\%)^{\text {Heterogeneity }}$ \\
\hline Length of ICU stay & 211 & 3 & $2.25(-6.74$ to 11.24$)$ & 0.62 & 86 & 0.007 \\
\hline Length of hospital stay & 211 & 3 & $2.66(-8.80$ to 14.12$)$ & 0.65 & 59 & 0.12 \\
\hline Duration of MV & 211 & 3 & $1.03(-5.06$ to 7.12$)$ & 0.74 & 80 & 0.02 \\
\hline GCS score & 293 & 4 & $0.00(-0.82$ to 0.82$)$ & 1 & 0 & 1 \\
\hline ISS & 189 & 3 & $2.61(-1.46$ to 6.68$)$ & 0.21 & 0 & 0.7 \\
\hline APACHE II score & 266 & 3 & $-1.38(-3.19,0.43)$ & 0.13 & 22 & 0.26 \\
\hline
\end{tabular}

We presume that the patients were allocated randomly, because earlier reports from the same investigators clearly described the use of random sequences. In an earlier study by Acosta-Escribano and coworkers, ${ }^{9}$ randomization was achieved by using sealed envelopes, and in earlier studies by Minard and coworkers, ${ }^{18,19}$ the patients were allocated randomly by using a randomization table generated by computer before institution of the study. Therefore, the risk of selection bias for random sequence generation was reported as low. ${ }^{1,21}$ Lack of blinding was considered to have a low effect on mortality outcomes; ${ }^{3}$ thus, this outcome was considered to have a low risk of bias..$^{1,16,21,25}$

Our meta-analysis had many limitations. Although 5 RCTs with a total of 325 participants (sample sizes ranged from 27 to 104) were included, the numbers of subjects in our study and all included studies were quite small. Because of the small sample sizes, 4 studies did not find a significant difference in the primary outcome, and only 1 study found a decreased risk of pneumonitis associated with feeding via the small bowel route in patients with severe TBI. Therefore, it is possible that the positive findings were obtained from a single RCT.

Another limitation is that, of 80 ventilated trauma patients in the Kortbeek et al. ${ }^{16}$ study, 62 patients with severe TBI were included in our study. Nevertheless, the point estimate was unaffected when the Kortbeek et al. study was removed $\left(\mathrm{RR} 0.67 ; 95 \%\right.$ CI 0.51-0.89; $\left.\mathrm{p}=0.006 ; \mathrm{I}^{2}=0 \%\right)$.

Although the ideal route for enteral feeding continues to be debated, we believe that the optimal clinical decision for the delivery of enteral nutrition should be personalized according to the individual profile, which includes nutritional status, severity, complications, feeding tolerance, and day-to-day changes in clinical conditions. ${ }^{28}$ Additional studies by nutritionists and clinicians are needed for better management of the delivery of enteral nutrition for patients with severe TBI.

\section{Conclusions}

The limited available evidence suggests that, in comparison with gastric feeding, small bowel feeding decreases the risk of pneumonia in patients with severe TBI. Our study lends support for the use of small intestinal feeding to reduce the incidence of pneumonitis in patients with severe TBI. However, our results should be interpreted with caution, given the various limitations of the study. In addition, well-designed RCTs are necessary to clarify the optimal nutritional strategies for patients with severe TBI.

\section{Acknowledgments}

We thank Zhen-Hua Duan from the Chengdu Center for Disease Control and Prevention for helping with the literature search in the Embase database and Dr. Sima Sarvari for assistance with manuscript preparation.

\section{References}

1. Acosta-Escribano J, Fernández-Vivas M, Grau Carmona T, Caturla-Such J, Garcia-Martinez M, Menendez-Mainer A, et al: Gastric versus transpyloric feeding in severe traumatic brain injury: a prospective, randomized trial. Intensive Care Med 36:1532-1539, 2010

2. Acosta Escribano J, Herrero Meseguer I, Conejero GarcíaQuijada R: Guidelines for specialized nutritional and metabolic support in the critically-ill patient: update. Consensus SEMICYUC-SENPE: neurocritical patient. Nutr Hosp 26 (Suppl 2):72-75, 2011

3. Alhazzani W, Almasoud A, Jaeschke R, Lo BW, Sindi A, Altayyar S, et al: Small bowel feeding and risk of pneumonia in adult critically ill patients: a systematic review and metaanalysis of randomized trials. Crit Care 17:R127, 2013

4. Apelgren KN, Rombeau JL, Twomey PL, Miller RA: Comparison of nutritional indices and outcome in critically ill patients. Crit Care Med 10:305-307, 1982

5. Baker SP, O'Neill B, Haddon W Jr, Long WB: The injury severity score: a method for describing patients with multiple injuries and evaluating emergency care. J Trauma 14:187196, 1974

6. Bratton SL, Chestnut RM, Ghajar J, McConnell Hammond FF, Harris OA, Hartl R, et al: Guidelines for the management of severe traumatic brain injury. XII. Nutrition. J Neurotrauma 24 (Suppl 1):S77-S82, 2007

7. Dempsey DT, Mullen JL, Buzby GP: The link between nutritional status and clinical outcome: can nutritional intervention modify it? Am J Clin Nutr 47 (2 Suppl):352-356, 1988

8. Faul M, Xu L, Wald MM, Coronado VG: Traumatic Brain Injury in the United States: Emergency Department Visits, Hospitalizations and Deaths, 2002-2006. Atlanta: U.S. Department of Health and Human Services, Centers for Disease Control and Prevention, National Center for Injury Prevention and Control, 2010.

9. Fernández-Vivas M, Caturla-Such J, González de la Rosa J, Acosta-Escribano J, Alvarez-Sánchez B, Cánovas-Robles $\mathrm{J}$ : Noninvasive pressure support versus proportional assist ventilation in acute respiratory failure. Intensive Care Med 29:1126-1133, 2003

10. Giacino JT, Whyte J, Bagiella E, Kalmar K, Childs N, Khade$\mathrm{mi}$ A, et al: Placebo-controlled trial of amantadine for severe traumatic brain injury. N Engl J Med 366:819-826, 2012

11. Grahm TW, Zadrozny DB, Harrington T: The benefits of early jejunal hyperalimentation in the head-injured patient. Neurosurgery 25:729-735, 1989 
12. Higgins JPT, Altman DG, Gøtzsche PC, Jüni P, Moher D, Oxman AD, et al: The Cochrane Collaboration's tool for assessing risk of bias in randomised trials. BMJ 343:d5928, 2011

13. Higgins JPT, Thompson SG, Deeks JJ, Altman DG: Measuring inconsistency in meta-analyses. BMJ 327:557-560, 2003

14. Jiyong J, Tiancha H, Huiqin W, Jingfen J: Effect of gastric versus post-pyloric feeding on the incidence of pneumonia in critically ill patients: observations from traditional and Bayesian random-effects meta-analysis. Clin Nutr 32:8-15, 2013

15. Knaus WA, Draper EA, Wagner DP, Zimmerman JE: APACHE II: a severity of disease classification system. Crit Care Med 13:818-829, 1985

16. Kortbeek JB, Haigh PI, Doig C: Duodenal versus gastric feeding in ventilated blunt trauma patients: a randomized controlled trial. J Trauma 46:992-998, 1999

17. Kreymann KG, Berger MM, Deutz NE, Hiesmayr M, Jolliet $P$, Kazandjiev G, et al: ESPEN guidelines on enteral nutrition: intensive care. Clin Nutr 25:210-223, 2006

18. Kudsk KA, Croce MA, Fabian TC, Minard G, Tolley EA, Poret HA, et al: Enteral versus parenteral feeding. Effects on septic morbidity after blunt and penetrating abdominal trauma. Ann Surg 215:503-513, 1992

19. Kudsk KA, Minard G, Croce MA, Brown RO, Lowrey TS, Pritchard FE, et al: A randomized trial of isonitrogenous enteral diets after severe trauma. An immune-enhancing diet reduces septic complications. Ann Surg 224:531-543, 1996

20. Marino LV, Ramchandra P, Nathoo N: Blind transpyloric nasojejunal versus nasogastric tube intubation in severe head injuries: a preliminary report. J Clin Neurosci 12:435-437, 2005

21. Minard G, Kudsk KA, Melton S, Patton JH, Tolley EA: Early versus delayed feeding with an immune-enhancing diet in patients with severe head injuries. JPEN J Parenter Enteral Nutr 24:145-149, 2000

22. Montejo JC, Miñambres E, Bordejé L, Mesejo A, Acosta J, Heras A, et al: Gastric residual volume during enteral nutrition in ICU patients: the REGANE study. Intensive Care Med 36:1386-1393, 2010
23. Reignier J, Mercier E, Le Gouge A, Boulain T, Desachy A, Bellec F, et al: Effect of not monitoring residual gastric volume on risk of ventilator-associated pneumonia in adults receiving mechanical ventilation and early enteral feeding: a randomized controlled trial. JAMA 309:249-256, 2013

24. Rosenfeld JV, Maas AI, Bragge P, Morganti-Kossmann MC, Manley GT, Gruen RL: Early management of severe traumatic brain injury. Lancet 380:1088-1098, 2012

25. Taylor SJ, Fettes SB, Jewkes C, Nelson RJ: Prospective, randomized, controlled trial to determine the effect of early enhanced enteral nutrition on clinical outcome in mechanically ventilated patients suffering head injury. Crit Care Med 27:2525-2531, 1999

26. Teasdale G, Jennett B: Assessment and prognosis of coma after head injury. Acta Neurochir (Wien) 34:45-55, 1976

27. Teasdale G, Jennett B: Assessment of coma and impaired consciousness. A practical scale. Lancet 2:81-84, 1974

28. Wang X, Dong Y, Han X, Qi XQ, Huang CG, Hou LJ: Nutritional support for patients sustaining traumatic brain injury: a systematic review and meta-analysis of prospective studies. PLoS ONE 8:e58838, 2013

\section{Author Contributions}

Conception and design: HB Chen, Wang, Zheng, Jiang. Acquisition of data: Wang, Zheng. Analysis and interpretation of data: HB Chen, Wang, Zheng, XC Chen. Drafting the article: HB Chen, Wang, Jiang. Reviewed submitted version of manuscript: HB Chen, Wang, Zheng, Jiang. Approved the final version of the manuscript on behalf of all authors: HB Chen. Statistical analysis: HB Chen, Wang, XC Chen. Study supervision: HB Chen.

\section{Correspondence}

Hai-Bin Chen, Department of Histology and Embryology, Shantou University Medical College, 22 Xinling Rd., Shantou, Guangdong Province 515041, People's Republic of China. email: chenhb@stu.edu.cn. 